\title{
Reactive and Regulative Temperament in Youths: Psychometric Evaluation of the Early Adolescent Temperament Questionnaire-Revised
}

\author{
Peter Muris • Cor Meesters
}

Published online: 26 July 2008

(C) The Author(s) 2008

\begin{abstract}
The present study examined the psychometric properties of the self-report version of the Early Adolescent Temperament Questionnaire-Revised (EATQ-R), which is a scale for measuring reactive and regulative temperament traits, in a large sample of children and adolescents $(N=$ 1,055). The results indicated that the internal consistency was acceptable for most EATQ-R temperament scales. Further, principal components analysis of the instrument yielded a structure with nine components, which generally reflected the temperament scales of the EATQ-R. The testretest stability of the scale was moderate to good, whereas the parent-child agreement was rather low. Finally, the scale correlated in a theoretically meaningful way with children's self-reports of personality and psychopathology. It can be concluded that the EATQ-R is a useful scale for measuring aspects of reactive and regulative temperament in children and adolescents, although there is certainly room for improving the instrument.
\end{abstract}

Keywords Temperament - Children and adolescents . Early adolescent temperament questionnaire-revised . Psychometrics

Peter Muris, Institute of Psychology, Erasmus University Rotterdam, and Cor Meesters, Department of Clinical Psychological Science, Maastricht University, The Netherlands. Pim Blijlevens, Dorrette Driesen, Hinke Hiemsta, Maudi van Hoften, Lotte Vermeulen, and Sylvia Wessels are kindly acknowledged for their assistance with the data collection.

\footnotetext{
P. Muris $(\bowtie)$

Institute of Psychology, Erasmus University Rotterdam, Burgemeester Oudlaan 50, Suite T-13-37, P.O. Box 1738, 3000 DR Rotterdam, The Netherlands

e-mail: muris@fsw.eur.nl

C. Meesters

Maastricht University,

Maastricht, The Netherlands
}

This article describes an investigation of the psychometric properties of a self-report questionnaire for measuring children's temperament. The theoretical foundation for this scale, the Early Adolescent Temperament QuestionnaireRevised (EATQ-R), was laid by Mary Rothbart and her colleagues who have defined temperament as individual differences in reactivity and self-regulation (Rothbart and Derryberry 1981), with reactivity referring to the excitability, responsivity, or arousability of the behavioral and physiological systems of an organism, and self-regulation pertaining to neural and behavioral processes that function to modulate this underlying reactivity. In the past decade, the contours of this temperamental model have gradually crystallized (Rothbart 1989; Rothbart and Bates 1998, 2006; Rothbart et al. 1994, 2000, 2006), and not surprisingly this has led to the application of the model in various developmental contexts (e.g., Eisenberg et al. 2004b; Muris and Ollendick 2005; Nigg 2006).

At a more general level, temperament can be defined as "biologically rooted individual differences in behavior tendencies that are present early in life and are relatively stable across various kinds of situations and over the course of time" (Bates 1987; p. 1101). The difference between temperament and personality is rather vague. Temperament is viewed as the part of personality that is genetically determined, and is considered as the observable manifestation of the child's emerging personality (Matthews et al. 2003). Empirical evidence for the relation between temperament and personality has been provided by Caspi and colleagues (Caspi 2000; Caspi et al. 2003; Caspi and Silva 1995) who followed three temperament groups of young children in their development to adulthood. Children who at 3 years of age had been classified as undercontrolled and overcontrolled still showed signs of these temperament categories at age 26 , whereas children who had been classified as well- 
adjusted when they were young, still represented the normative group in adulthood. Although the links between childhood temperament and adult personality were at best modest, this study demonstrates that there is reasonable stability in individuals' behavioral characteristics over long time periods. Furthermore, it is increasingly acknowledged that at various ages temperament plays a critical role in youths' social and emotional functioning, and more specifically in the development of psychopathological syndromes (Muris and Ollendick 2005; Nigg 2006).

Many blueprints have been hypothesized for the structure of temperament in children. A frequently cited framework is the one formulated early on by Chess and Thomas (1985; see also Thomas and Chess 1977) who identified three fundamental temperament types, namely 'easy', 'difficult', and 'slow-to-warm-up', which all reflect clear variations in the type and intensity of children's responses to stimuli in the environment. Other descriptive frameworks for children's temperament have adopted a more dimensional approach, and have aimed at identifying basic temperamental traits. A good example of such an approach is Buss and Plomin's (1984) EmotionalityActivity-Sociability (EAS) model. The first dimension of 'emotionality' refers to psychological instability and a proneness to experience feelings of fear, anger, and sadness, the second dimension of 'activity' is concerned with characteristics such as tempo, vigor, and endurance, while the third and final dimension is 'sociability', which pertains to traits such as tendencies to affiliate and to be responsive to others. Interestingly, a comparison of the EAS model with current theories of personality such as the 'Big Five' (Costa and McCrae 1992) and the 'Giant Three' (Eysenck 1991) makes clear that the three temperament dimensions are clearly linked to the personality factors of 'neuroticism' and 'extraversion'. That is, neuroticism can be viewed as an equivalent for emotionality, whereas extraversion can be regarded as a mixture of activity level and sociability.

The aforementioned temperament theory of Rothbart (Putnam et al. 2002; Rothbart and Bates 1998) proposes that temperament not only consists of reactive characteristics pertaining to the basis dimensions of emotionality, activity, and sociability, but also contains regulative features that can be subsumed under the concept of 'effortful control'. Effortful control refers to self-regulative processes and can best be defined as "the ability to inhibit a dominant response to perform a subdominant response" (Rothbart and Bates 1998). The idea is that effortful control enables children to regulate emotions and to control their behavior, which may have positive effects on their social interactions with other children (Eisenberg et al. 2004a; Fabes et al. 1999; Guthrie et al. 1997; Kochanska 1997). In children with low levels of effortful control such normal processes can be disturbed and this may increase their vulnerability to develop psychopathological symptoms (see for reviews Muris and Ollendick 2005; Nigg 2006).

To measure the full range of temperament traits as proposed in Rothbart's theory, various parent-rating scales have been developed that can be employed in children of various ages (Garnstein and Rothbart 2003; Rothbart 1981; Rothbart et al. 2001; Putnam and Rothbart 2006; Putnam et al. 2006). The EATQ-R (Ellis and Rothbart 2001) has been specifically developed to measure these reactive and regulative temperament factors from the child's point-of view. Such a self-report scale seems an important addition to the instruments for measuring temperament in youths, as self-description is generally regarded as an important source of information in the field of personality research (Carver and Scheier 1996). The EATQ-R is a revised and updated version of the EATQ (Capaldi and Rothbart 1992) and can be used in children and adolescents aged between 9 and 15 years (Ellis and Rothbart 2001). The full questionnaire consists of 11 scales for measuring various aspects of temperament, and two additional scales for assessing symptoms of aggression and depression among youths. Although researchers increasingly use the EATQ-R for measuring youths' temperament (e.g., Muris et al. 2007; Oldehinkel et al. 2004; Van Brakel and Muris 2006; Veenstra et al. 2006), a comprehensive study evaluating the reliability and validity of the self-report version of this scale is currently missing in the literature.

With this in mind, the current investigation was set-up. The EATQ-R was administered to a large sample of children and adolescents $(N=1,055)$ in order to study the following issues: (1) The structure of the questionnaire was explored by means of a principal components analysis; (2) The reliability (i.e., internal consistency and test-retest stability) of various EATQ-R temperament scales was examined; (3) The parent-child agreement of the scale was investigated; and (4) The validity of the EATQ-R temperament scales was established by studying its associations with measures of personality and psychopathology. The relation with personality was examined by studying associations between EATQ-R scales and Gray's (1991) biologically determined personality factors that are thought to reflect the activity of brain systems that serve to regulate withdrawal and approach behavior in response to environmental stimuli [i.e., the behavioral inhibition system (BIS) and the behavioral activation system (BAS)], and Kagan's (1994) temperament-based individual difference variable of "behavioral inhibition to the unfamiliar" that can be defined as the tendency to exhibit fearfulness, restraint, and withdrawal in the face of novel events or situations, including unfamiliar rooms, toys, peers, and adults (which may be intimately related to or even overlapping with Gray's BIS). It was anticipated that EATQ-R scales covering aspects of emotionality would be positively 
associated with BIS, scales covering aspects of activity and sociability would be positively related to BAS, while EATQ-R shyness would be particularly linked to Kagan's concept of behavioral inhibition. The connection with psychopathology was investigated by studying associations between EATQ-R scales and symptom levels of internalizing (e.g., anxiety disorders, depression) and externalizing (e.g., aggression) problems. Here, it was anticipated that EATQ-R scales pertaining to emotionality would be positively related to symptoms of internalizing and externalizing, whereas EATQ-R scales referring to effortful control would be negatively related to such symptoms.

\section{Method}

\section{Participants}

One-thousand-and-fifty-five children and young adolescents (528 boys and 527 girls) were recruited from 17 regular primary and secondary schools in the eastern part of Belgium and the southern and western parts of the Netherlands. Children's ages ranged between 8 and 14 years (mean age $=11.06$ years, $\mathrm{SD}=1.00$ ). More precisely, the sample consisted of $1(0.1 \%) 8$-year-old, $49(4.6 \%) 9$-yearolds, 252 (23.9\%) 10-year-olds, 425 (40.3\%) 11-year-olds, $237(22.5 \%)$ 12-year-olds, 90 (8.5\%) 13-year-olds, and 1 (0.1\%) 14-year-old. The research project was officially approved by the Ethical Committee of Psychological Research of Erasmus University. Written informed consent was obtained from parents who indicated that (1) they had no objection that their child participated in the study, (2) their child was willing to take part in the study, and (3) in case parent scales were included in the study, they agreed to fill out such measures. Due to school constraints, no exact information about the socioeconomic background of the youths was available. However, almost $15 \%$ was nonCaucasian, which in The Netherlands and Belgium is generally indicative for a lower socioeconomic status.

\section{Questionnaires}

The long version of the EATQ-R (Ellis and Rothbart 2001) measures the following reactive and regulative temperament traits in 9- to 15-year-old children and adolescents: (1) 'activation control' is concerned with the ability to perform an action when there is a strong tendency to avoid it (e.g., "If I have a hard assignment to do, I get started right away"), (2) 'activity level' involves participation in activities requiring high levels of physical activity (e.g., "I would rather play a sport than watch TV"), (3) 'affiliation' has to do with the desire for warmth and closeness with others (e.g., "I enjoy exchanging hugs with people I like"), (4) 'attention' relates to the ability to focus and shift attention when desired (e.g., "It is easy for me to really concentrate on homework problems"), (5) 'fearfulness' refers to the tendency to experience unpleasant affect related to anticipation of distress (e.g., "I worry about getting into trouble"), (6) 'frustration' pertains to the tendency to experience unpleasant affect related to the interruption of ongoing tasks or goal blocking (e.g., "I get upset if I am not able to do a task really well"), (7) 'high intensity pleasure' involves the pleasure derived from activities involving high intensity or novelty (e.g., "I enjoy going to places where there are big crowds and lots of excitement"), (8) 'inhibitory control' is concerned with the ability to plan, and to suppress inappropriate responses (e.g., "When someone tells me to stop doing something, it is easy for me to stop"), (9) 'perceptual sensitivity' relates to the detection and awareness of slight, low-intensity stimulation in the environment (e.g., "I tend to notice little changes that other people do not notice"), (10) 'pleasure sensitivity' regards the amount of pleasure related to activities and stimuli involving low intensity, complexity, and novelty (e.g., "I like to look at trees and walk amongst them"), and (11) 'shyness' which refers to behavioral inhibition to novelty and challenge, especially social (e.g., "It is a lot easier for me to talk to familiar people than to strangers"). In addition, the EATQ-R includes two behavioral scales for measuring symptoms of aggression and depressive mood. Because the present study was concerned with the study of youths' temperament, these scales were discarded. Each item has to be answered on a five-point Likert scale ranging from $1=$ almost never true to $5=$ almost always true. Temperament trait scores can be computed by summing ratings across relevant items (after recoding inversely formulated items).

There is evidence indicating that EATQ-R scales cluster on a number of higher-order temperament factors. More precisely, activation control, attention, and inhibitory control seem to constitute the factor of effortful control, frustration and fear seem to comprise the factor of emotionality, whereas high intensity pleasure, activity level, and low levels of shyness seem to form the higher-order factor of extraversion/surgency (see Ellis and Rothbart 2001; Muris et al. 2007). Other EATQ-R scales show a less consistent pattern of loadings on these three higher-order temperament factors.

The parent version of the EATQ-R is identical to the self-report version except for the fact that items are rephrased in terms of the parents' perspective. Examples are "My child worries about getting into trouble", "My child enjoys going to places where there are big crowds and lots of excitement", and "It is easy for my child to really concentrate on homework problems". 
The child version of the BIS/BAS scales (Carver and White 1994) intends to measure individual differences in sensitivity of the behavioral inhibition and behavioral activation systems (i.e., BIS and BAS; Gray 1991). The items of the original scales were somewhat changed and simplified to make them more appropriate and understandable to children (e.g., "I am hurt when people scold me or tell me that I do something wrong", "I get thrilled when good things happen to me"; see Muris et al. 2005). Each item has to be scored on a four-point Likert scale with $0=$ not true, $1=$ somewhat true, $2=$ true, and $3=$ very true. A recent study by Muris et al. (2005) has shown that the child version of the BIS/BAS scales possesses a theoretically meaningful factor structure with two separate factors for BIS and BAS. Further, the reliability of the BIS and BAS scales appears satisfactory (with Cronbach's alphas> 0.75 ), and the scales generally show the expected relationships with other personality traits and psychopathological symptoms.

To measure Kagan's (1994) temperamental characteristic of behavioral inhibition, the Behavioural Inhibition Scale (see Gest 1997; Muris et al. 1999) was used. The scale consists of four items relating to shyness ("I am shy when I have to talk to an unfamiliar person"), communication ("I talk easily to an unfamiliar person"), fearfulness ("I feel nervous when I have to talk to an unfamiliar person"), and smiling ("I feel good and I am able to laugh, when I talk to an unfamiliar person"). Each item is rated on a four-point Likert scale with $1=$ never, $2=$ sometimes, $3=$ often, and $4=$ always. After recoding the positive items, scores are summed to yield a total BIS score ranging from 4 (not apprehensive, not shy and very sociable when meeting an unfamiliar person) to 16 (very apprehensive and shy and not capable of initiating social interaction with an unfamiliar person). Previous research has provided clear support for the reliability (with Cronbach's alpha $>0.80$ and a testretest correlation of 0.72 ) and validity of the BIS (Muris et al. 1999, 2001b, 2003a; Van Brakel and Muris 2006; Van Brakel et al. 2004).

The short version of the Revised Child Anxiety and Depression Scale (RCADS; Chorpita et al. 2000) is a 25item scale for measuring symptoms of DSM-defined anxiety disorders and depression. Items (e.g., "I am afraid of looking foolish in front of people", "I feel sad or empty") have to be scored on a 4-point scale with $0=$ never, $1=$ sometimes, $2=$ often, and $3=$ always. In the present study, anxiety (20 items) and depression (five items) scores were obtained by summing across relevant items. Previous research has indicated that the (shortened) RCADS has a clear-cut factor structure, is reliable in terms of internal consistency and temporal stability (all Cronbach's alphas $>$ 0.60 and test-retest correlations between 0.79 and 0.85 ), and displays good validity as evidenced by positive associations with concurrent childhood questionnaires (Muris et al. 2002).

The Child Rating scale for Aggression (CRA) is a selfreport version of the Teacher Rating scale for Aggression (Brown et al. 1996), which consists of 21 items referring to aggressive feelings and behaviors of children (e.g., "I get angry for no reason", "I am mean"). Each item has to be scored on a five-point scale with $1=$ never, $2=$ seldom, $3=$ sometimes, $4=$ often, and $5=$ almost always. Recent studies have demonstrated that the CRA is reliable in terms of internal consistency (Cronbach's alpha $>0.80$; Meesters et al. 2007; Roelofs et al. 2006) and temporal stability (test-retest correlation $=0.75$; Korchnakova 2007), and correlates significantly with other measures of self-reported disruptive behavior problems such as the Youth Self-Report externalizing scale (Vincken et al. 2004).

The self-report version of the Strengths and Difficulties Questionnaire (SDQ; Goodman 2001) consists of 25 items describing positive and negative attributes of children and adolescents that can be allocated to five subscales of five items each: emotional symptoms, conduct problems, hyperactivity-inattention, peer problems, and prosocial behavior. Each item has to be scored on a three-point scale with $0=$ not true, $1=$ somewhat true, and $2=$ certainly true. Subscale scores can be computed by summing scores on relevant items (after recoding reversed items; range 0-10). Higher scores on the prosocial behaviour subscale reflect strengths, whereas higher scores on the other four subscales reflect difficulties. A total difficulties score can also be calculated by summing the scores on the emotional symptoms, conduct problems, hyperactivity-inattention, and peer problems subscales (range 0-40). Research has shown that the SDQ has acceptable psychometric properties: reliability is reasonable with most Cronbach's alphas being $>$ 0.60 , whereas validity appears good as evidenced by substantial correlations with other scales for measuring internalizing and externalizing problems in youths (Goodman 2001; Muris et al. 2003b; Muris et al. 2004).

All the questionnaires were in Dutch and in case they were derived from English scales carefully translated following a translation/back-translation procedure. As can be seen from the references above, scales have been tested extensively in Dutch samples, and this research has generally provided support for the equivalence of the Dutch and English versions. In passing, it should be noted that, with few exceptions, most scales that were employed in the present study displayed adequate internal consistency. More precisely, Cronbach's alphas were 0.75 for BIS and 0.80 for BAS, 0.72 for the scale measuring Kagan's concept of behavioral inhibition, 0.55 for RCADS depression and 0.87 for RCADS anxiety, 0.88 for CRA total aggression, and varied between 0.41 (peer problems) and 0.70 (hyperactivityinattention) for the SDQ subscales. 


\section{Procedure}

Children and adolescents completed the EATQ-R and other questionnaires in their classrooms at school. Prior to the assessment session, information was given about the study after children were explicitly asked whether they still agreed to participate. None of the youths declined from participation. While completing various questionnaires, a research assistant and the teacher were always present to ensure confidential and independent responding, and to provide assistance to the children if necessary.

A subsample of children's parents received the EATQ-R by mail after they had responded favorably to mailed invitation. They completed the questionnaire at home and then returned it to the researchers in a sealed envelope.

The total sample of 1,055 children and adolescents was used for examining the internal consistency reliability and factor structure of the EATQ-R. Subsets of the sample were involved in specific aspects of the study such as the collection of the test-retest data (8-weeks interval) and the validity of the self-report version of the EATQ-R through its relations with the parent version of this scale and other questionnaires. The rationale for deriving subsamples was twofold: First, some of the schools only consented to spend a limited amount of time to the research project, and second, the inclusion of all scales would have yielded a rather lengthy survey, which probably would have undermined children's dedication. The test-retest sample contained 101 children (46 boys and 55 girls) with a mean age of 10.48 years $(\mathrm{SD}=1.07)$. Three further subsamples were used to examine the parent-child agreement of the EATQ-R and its relationship to measures of psychopathology $(N=390 ; 191$ boys and 199 girls; mean age $=10.90$,
$\mathrm{SD}=0.69)$ and personality (BIS/BAS scales: $N=240 ; 120$ boys and 120 girls; mean age $=11.57, \mathrm{SD}=1.48$; Behavioral inhibition: $N=108 ; 49$ boys and 59 girls; mean age $=10.47$, $\mathrm{SD}=1.08)$. There were no significant gender differences among the four subsamples $\left[\chi^{2}(3)=4.14, p=0.38\right]$. However, an analysis of variance indicated that the samples did differ with regard to age $[F(3,1,050)=27.14, p<0.001]$ : the subsample in which the relations between the EATQ-R and BIS/BAS scales were examined was significantly older than the other subsamples (all $p s<0.01$ ). It is important to note that almost all data were new and specifically collected for the purpose of the present study. The only exception were the EATQ-R data obtained by Muris et al. (2007), which were included in the total sample for investigating the internal consistency and structure of the scale.

\section{Results}

\section{Gender Differences and Internal Consistency}

Inspection of the mean scores on various EATQ-R temperament scales (Table 1) indicated that fearfulness, shyness, and high intensity pleasure items were the least frequently endorsed temperament characteristics, whereas affiliation, activity level, and activation control were most often endorsed by these non-clinical youths. Furthermore, $t$-tests indicated that there were significant gender differences on a number of temperament scales. More precisely, girls exhibited higher levels of affiliation $[t(1,053)=9.90$, $p<0.001]$, fearfulness $[t(1,053)=6.37, p<0.001]$, inhibitory control $[t(1,053)=3.89, p<0.001]$, pleasure sensitivity $[t(1,053)=2.94, p<0.005]$, and shyness $[t(1,053)=3.54$,

Table 1 General statistics (mean scores, gender differences, and reliability coefficients) for various temperament scales of the EATQ-R

\begin{tabular}{|c|c|c|c|c|c|}
\hline & Total sample $M(S D)$ & Boys $M(S D)$ & Girls $M(S D)$ & $\alpha$ Original scale & $\alpha$ Final scale ${ }^{a}$ \\
\hline \multicolumn{6}{|l|}{ EATQ-R } \\
\hline Activation control & $3.53(0.58)$ & $3.49(0.58)_{\mathrm{a}}$ & $3.57(0.58)_{\mathrm{a}}$ & $0.61[8]$ & $0.68[6]$ \\
\hline Activity level & $3.69(0.69)$ & $3.78(0.69)_{\mathrm{a}}$ & $3.61(0.69)_{\mathrm{b}}$ & $0.71[6]$ & $0.71[6]$ \\
\hline Affiliation & $3.76(0.58)$ & $3.59(0.58)_{\mathrm{a}}$ & $3.92(0.52)_{\mathrm{b}}$ & $0.65[8]$ & $0.65[8]$ \\
\hline Attention & $3.37(0.56)$ & $3.39(0.58)_{\mathrm{a}}$ & $3.35(0.55)_{\mathrm{a}}$ & $0.51[7]$ & $0.61[5]$ \\
\hline Fearfulness & $2.65(0.77)$ & $2.50(0.75)_{\mathrm{a}}$ & $2.80(0.77)_{\mathrm{b}}$ & $0.62[6]$ & $0.62[6]$ \\
\hline Frustration & $3.12(0.63)$ & $3.17(0.63)_{\mathrm{a}}$ & $3.07(0.63)_{\mathrm{a}}$ & $0.72[9]$ & $0.72[9]$ \\
\hline High intensity pleasure & $2.96(0.60)$ & $3.07(0.57)_{\mathrm{a}}$ & $2.84(0.60)_{\mathrm{b}}$ & $0.67[11]$ & $0.73[9]$ \\
\hline Inhibitory control & $3.19(0.50)$ & $3.13(0.51)_{\mathrm{a}}$ & $3.25(0.49)_{\mathrm{b}}$ & $0.58[11]$ & $0.63[7]$ \\
\hline Perceptual sensitivity & $3.16(0.68)$ & $3.18(0.70)_{\mathrm{a}}$ & $3.14(0.66)_{\mathrm{a}}$ & $0.57[6]$ & $0.61[5]$ \\
\hline Pleasure sensitivity & $3.12(0.75)$ & $3.05(0.72)_{\mathrm{a}}$ & $3.19(0.77)_{\mathrm{b}}$ & $0.70[7]$ & $0.74[6]$ \\
\hline Shyness & $2.80(0.73)$ & $2.72(0.71)_{\mathrm{a}}$ & $2.88(0.75)_{\mathrm{b}}$ & $0.71[7]$ & $0.71[7]$ \\
\hline
\end{tabular}

$N=1,055,528$ boys and 527 girls. Means with different subscripts reflect significant gender difference at $p<0.05 / 11$. Number of items for the pertinent scale are given between parentheses.

EATQ-R Early Adolescent Temperament Questionnaire-Revised

${ }^{a}$ After removing items with unsatisfactory item-total scale correlations (i.e., $<0.20$ ). 
$p<0.001]$, whereas boys showed higher levels of activity level $[t(1,053)=3.96, p<0.001]$ and high intensity pleasure $[t(1,053)=6.41, p<0.001]$ (cf. Else-Quest et al. 2006).

Internal consistency coefficients were modest but sufficient for most EATQ-R scales. However, for three scales (i.e. attention, inhibitory control, and perceptual sensitivity), Cronbach's alphas were below acceptable limits $(0.51,0.58$, and 0.57 , respectively). To improve the internal consistency of various scales, the item-total scale correlations were examined in detail, after which unsatisfactory items (with an item-total correlation $<0.20$ ) were removed. This procedure led to the elimination of 12 items, and resulted in sufficient alpha values for all EATQ-R scales (see right column of Table 1).

\section{Factor Structure}

A principal components analysis (with an oblimin rotation) performed on the items of the EATQ- $\mathrm{R}^{1}$ yielded 19 components with an eigenvalue $>1.0$, which accounted for $52.77 \%$ of the total variance. However, this solution was not satisfactory, and so the next step was to extract 11 components, which was in keeping with the number of temperament scales included in the EATQ-R. Although several interpretable factors emerged, there were also a number of less clear components that only consisted of one or two items. After reducing the number of components to nine, a theoretically meaningful structure emerged, which accounted for $37.24 \%$ of the variance. As can be seen in Table 2, most EATQ-R items loaded on a component that was unique for their intended temperament scale. There were three exceptions to this rule, component 1 mainly consisted of a mixture of frustration and inhibitory control, component 8 not only contained fearfulness but also a number of frustration items, whereas component 9 was a compound of activation control, attention, and inhibitory control items and thus essentially reflected effortful control. $^{2}$ Although the hypothesized structure did not fully emerge, it was decided to use the 11 original scales in the further course of this article in order to enhance comparability with previous studies.
A second-order principal components analysis (with oblimin rotation) carried out on the EATQ temperament scale scores yielded three factors with eigenvalues $>1.0$ (i.e., 2.65, 2.02, and 1.46), which accounted for $55.76 \%$ of the total variance. As shown in Table 3, the first component consisted of the effortful control-related scales of activation control, attention, and inhibitory control (positive loadings) and the emotionality-related scales of fearfulness and frustration (negative loadings). The second component contained the temperament scales of pleasure sensitivity, affiliation, fearfulness, and perceptual sensitivity (all positive loadings), whereas the third and final component consisted of high intensity pleasure and activity levels (positive loadings) and shyness and fearfulness (negative loadings). ${ }^{3}$

When solely focusing on the temperament scales that are relevant for the three main temperament factors of emotionality, extraversion, and effortful control, a clearcut three factor structure emerged (eigenvalues were 2.64, 1.49, and 1.06; explained variance $=64.84 \%$ ): activation control, attention, and inhibitory control loaded clearly on the first component (effortful control), activity level and high intensity pleasure loaded convincingly on the second component (extraversion), whereas fearfulness, frustration, and shyness loaded on the third component (emotionality).

\section{Test-retest Stability and Parent-child Agreement}

Paired $t$-tests indicated that none of the EATQ-R scale scores changed significantly during the 8 -week period. Intra-class correlation coefficients $(N=101)$ were all significant and ranged between 0.55 (perceptual sensitivity) and 0.85 (frustration), indicating modest to good test-retest stability (see Table 4).

Correlations between the child and parent version $(N=$ 390) varied between 0.33 (affiliation, frustration, and perceptual sensitivity) and 0.59 (activity level), suggesting that the parent-child agreement of various EATQ-R scales was low to moderate (Table 4).

\footnotetext{
${ }^{1}$ Only the 74 items that were retained in the final EATQ-R scales (see Table 1) were included in the principal components analysis. Except for items referring to depression and aggression, the following items were excluded: 32 and 55 (activation control), 67 and 86 (attention), 20, 71, 81, and 89 (inhibitory control), 34 (pleasure sensitivity), 8 and 29 (high intensity pleasure), and 92 (perceptual sensitivity).

${ }^{2}$ A confirmatory factor analysis (AMOS) was also carried out to test the fit of a correlated 11-factor model in which the 74 EATQ-R items loaded on their original temperament scales. The results underlined the complexity of the scale, as the fit of this model was rather modest: $\chi^{2}$ $d f=2.50, \mathrm{GFI}=0.84$, and $\mathrm{RMSEA}=0.04$.
}

\footnotetext{
${ }^{3}$ For reasons of comparison with the previous study by Ellis and Rothbart (2001), a second-order principal components analysis was performed that not only included EATQ-R temperament scales but also the behavioral scales of depression and aggression. This analysis also yielded three components with eigenvalues $>1.0$ (i.e., 3.37, 2.04, and 1.75), which accounted for $55.05 \%$ of the variance. The components were highly similar to those obtained with the previous analysis, with aggression and depression loading on the first component that essentially consisted of emotionality and effortful control scales.
} 
Table 2 Principal components factor analysis (oblimin rotation) performed on the temperament items of the EATQ-R

Abbreviated item

Loading

Component $1^{\text {a }}$

Frustration [91]

Frustration [79]

Inhibitory control [12]

Inhibitory control [22]

Inhibitory control [39]

Frustration [58]

Frustration [42]

Frustration [40]

Frustration [101]

Frustration [73]

Attention [44]

Inhibitory control [46]

Inhibitory control [21]

Component $2^{\mathrm{b}}$

Affiliation [51]

Affiliation [47]

Affiliation [75]

Affiliation [78]

Affiliation [94]

Affiliation [38]

Affiliation [23]

Affiliation [88]

Component $3^{\mathrm{c}}$

High intensity pleasure [53]

High intensity pleasure [14]

High intensity pleasure [99]

High intensity pleasure [61]

High intensity pleasure [95]

High intensity pleasure [17]

High intensity pleasure [2]

High intensity pleasure [103]

Fearfulness [54]

High intensity pleasure [27]

Component $4^{\mathrm{d}}$

Pleasure sensitivity [70]

Pleasure sensitivity [30]

Pleasure sensitivity [80]

Pleasure sensitivity [48]

Pleasure sensitivity [50]

Pleasure sensitivity [28]

Component $5^{\mathrm{e}}$

Shyness [76]

Shyness [87]

Shyness [6]

Shyness [69]

Shyness [52]

Shyness [9]

Shyness [43]

Component $6^{\mathrm{f}}$

Perceptual sensitivity [11]

Perceptual sensitivity [31]

Perceptual sensitivity [35]

Perceptual sensitivity [4]

Perceptual sensitivity [41]

Annoyed when waiting in lines

0.66

Irritated when stopped doing something pleasant $\quad 0.62$

When excited, hard to wait one's turn (R) $\quad-0.57$

Hard not to open presents $(\mathrm{R}) \quad-0.54$

When having good time, hard to go home (R) $\quad-0.54$

$\begin{array}{ll}\text { Upset when parents won't let me do something } & 0.52\end{array}$

Bothered by busy line when making phone call 0.50

$\begin{array}{ll}\text { Patient person }(\mathrm{R}) & 0.49\end{array}$

$\begin{array}{ll}\text { Frustrated when people interrupt me } & 0.43\end{array}$

$\begin{array}{ll}\text { Bothered when people are slow to get ready } & 0.43\end{array}$

When interrupted, forget what saying (R) $\quad-0.39$

Not able to stop oneself $(\mathrm{R}) \quad-0.37$

Saying the first thing that comes to mind (R) $\quad-0.34$

$\begin{array}{ll}\text { Do anything to help dear person } & 0.60\end{array}$

$\begin{array}{ll}\text { Enjoying to hug people } & 0.59\end{array}$

$\begin{array}{ll}\text { Important to have close relationships } & 0.53\end{array}$

$\begin{array}{ll}\text { Like looking at other people's photographs } & 0.49\end{array}$

$\begin{array}{ll}\text { Like listening to other people talking } & 0.49\end{array}$

$\begin{array}{ll}\text { Like to spend time with good friend every day } & 0.48\end{array}$

$\begin{array}{ll}\text { Wanting to share private thoughts } & 0.44\end{array}$

$\begin{array}{ll}\text { Warm and friendly person } & 0.40\end{array}$

$\begin{array}{ll}\text { Not afraid to try risky sport } & 0.67\end{array}$

$\begin{array}{ll}\text { Scary to ski down a steep slope }(\mathrm{R}) & 0.66\end{array}$

$\begin{array}{ll}\text { Not afraid to try mountain climbing } & 0.63\end{array}$

$\begin{array}{ll}\text { Exciting to drive in race car } & 0.59\end{array}$

$\begin{array}{ll}\text { Do not want frightening rides at the fair }(\mathrm{R}) & 0.54\end{array}$

$\begin{array}{ll}\text { Not afraid to skateboard or ride bike down a steep hill } & 0.52\end{array}$

$\begin{array}{ll}\text { Enjoy big crowds and lots of excitement } & 0.46\end{array}$

$\begin{array}{lr}\text { Prefer exciting and unpredictable friends } & 0.44\end{array}$

Frightened when riding with person who likes to speed -0.37

$\begin{array}{ll}\text { Want to go on trips to exotic places } & 0.31\end{array}$

$\begin{array}{ll}\text { Enjoy listening to birds singing } & 0.75\end{array}$

$\begin{array}{ll}\text { Like to look at trees } & 0.73\end{array}$

$\begin{array}{ll}\text { Like to look at clouds in the sky } & 0.70\end{array}$

$\begin{array}{ll}\text { Like crunching sound of autumn leaves } & 0.70\end{array}$

$\begin{array}{ll}\text { Like to feel breeze blowing in face } & 0.50\end{array}$

$\begin{array}{ll}\text { Like the sounds of words } & 0.40\end{array}$

$\begin{array}{ll}\text { Shy } & 0.82 \\ \end{array}$

$\begin{array}{ll}\text { Not shy (R) } & 0.78\end{array}$

$\begin{array}{ll}\text { Shy about meeting people } & 0.74\end{array}$

Easier to talk to people I know than to strangers $\quad 0.49$

$\begin{array}{ll}\text { Know what to say, even to strangers (R) } & 0.46\end{array}$

$\begin{array}{ll}\text { Shy with kids of opposite sex } & 0.41\end{array}$

$\begin{array}{ll}\text { Uncomfortable when delivering message to adults } & 0.30\end{array}$

$\begin{array}{ll}\text { Notice even little changes in environment } & 0.67\end{array}$

$\begin{array}{ll}\text { Notice little changes that other people not notice } & 0.65\end{array}$

$\begin{array}{ll}\text { Very aware of noises } & 0.57\end{array}$

$\begin{array}{ll}\text { Notice when people are coughing during movies } & 0.53\end{array}$

$\begin{array}{ll}\text { Tell another person is angry by their expression } & 0.44\end{array}$ 
Table 2 (continued)

\begin{tabular}{|c|c|c|}
\hline & Abbreviated item & Loading \\
\hline \multicolumn{3}{|l|}{ Component $7^{\mathrm{g}}$} \\
\hline Activity level [100] & Prefer outdoor activities & 0.70 \\
\hline Activity level [36] & Like to be physically active & 0.68 \\
\hline Activity level [83] & Go out of the house during long winter weekends & 0.68 \\
\hline Activity level [1] & Rather play a sport than watch TV & 0.66 \\
\hline Activity level [16] & Do things with a lot of energy & 0.50 \\
\hline Activity level [64] & Have the energy for hard physical work & 0.50 \\
\hline \multicolumn{3}{|l|}{ Component $8^{\text {h }}$} \\
\hline Fearfulness [57] & Worry about my family & 0.65 \\
\hline Fearfulness $[85]$ & Worry about parents dying or leaving & 0.60 \\
\hline Fearfulness [3] & Worry about getting into trouble & 0.56 \\
\hline Frustration [102] & Upset when cannot do task very well & 0.56 \\
\hline Frustration $[98]$ & Frustrated when making mistake in school work & 0.51 \\
\hline Attention [56] & Hard to shift gears when going to another class (R) & -0.42 \\
\hline Fearfulness [77] & Nervous of some kids at school & 0.40 \\
\hline Fearfulness [93] & Scared to enter a dark room at home & 0.39 \\
\hline \multicolumn{3}{|l|}{ Component $9^{i}$} \\
\hline Activation control [63] & Finish homework in time & 0.69 \\
\hline Attention [25] & Easy to concentrate on homework problems & 0.60 \\
\hline Activation control $[66]$ & Start right away with hard assignment & 0.57 \\
\hline Activation control [82] & Put off working on projects (R) & 0.56 \\
\hline Attention [97] & Pay close attention when told how to do something & 0.56 \\
\hline Activation control [24] & Do something fun before starting homework (R) & 0.53 \\
\hline Attention [62] & When studying difficulty to concentrate (R) & 0.51 \\
\hline Activation control [7] & Have hard time finishing things on time $(\mathrm{R})$ & 0.51 \\
\hline Activation control $[65]$ & Being on time for school and appointments & 0.50 \\
\hline Inhibitory control [19] & When told to stop easy to do so & 0.37 \\
\hline Inhibitory control [45] & Blurt out answers before teacher calls & 0.36 \\
\hline
\end{tabular}

$N=1,055$. Original item numbers are given between parentheses.

EATQ-R Early Adolescent Temperament Questionnaire-Revised, $R$ reversed item for the pertinent temperament scale

${ }^{a}$ Eigenvalue $=6.81$, percentage of variance $=9.20$

${ }^{\mathrm{b}}$ Eigenvalue $=5.35$, percentage of variance $=7.23$

${ }^{\mathrm{c}}$ Eigenvalue $=4.42$, percentage of variance $=5.97$

${ }^{\mathrm{d}}$ Eigenvalue $=2.31$, percentage of variance $=3.12$

${ }^{\mathrm{e}}$ Eigenvalue $=2.01$, percentage of variance $=2.72$

${ }^{\mathrm{f}}$ Eigenvalue $=1.94$, percentage of variance $=2.62$

${ }^{\mathrm{g}}$ Eigenvalue $=1.73$, percentage of variance $=2.34$

${ }^{\mathrm{h}}$ Eigenvalue $=1.56$, percentage of variance $=2.11$

${ }^{\mathrm{i}}$ Eigenvalue $=1.44$, percentage of variance $=1.95$

\section{Validity I: Correlations with Personality Scales}

As shown in Table 5, BIS scores were positively correlated with EATQ-R fearfulness, frustration, shyness, and pleasure sensitivity ( $r$ s between 0.24 and $0.58, p s<0.001$ ), whereas significant negative correlations were found with attention and inhibitory control ( $r$ s being -.26 and -0.31 , respectively, $p \mathrm{~s}<0.001)$. As expected, BAS scores were positively related to frustration and high intensity pleasure $(r$ s being 0.52 and $0.29, p \mathrm{~s}<0.001)$ and negatively linked to attention and inhibitory control ( $r \mathrm{~s}$ being -0.25 and -0.53 , $p \mathbf{s}<0.001$ ). Surprisingly, BAS scores were also positively associated with fearfulness, although this correlation was significantly smaller than that between BIS scores and fearfulness $(Z=5.28, p<0.001)$ and clearly disappeared when controlling for the shared variance between BIS and BAS scores $(r=0.07)$.

Kagan's temperamental construct of behavioral inhibition was positively related to EATQ-R shyness $(r=0.45, p<0.001)$ and negatively linked to high intensity pleasure $(r=-0.32$, $p<0.001)$.

Validity II: Correlations with Psychopathological Symptoms

Correlations between EATQ-R temperament scales and various psychopathology measures are displayed in Table 6 . As can be seen, the expected pattern of findings emerged. 
Table 3 Second-order principal components factor analysis (oblimin rotation) performed on the temperament scales of the EATQ-R

\begin{tabular}{lccc}
\hline & Component 1 & Component 2 & Component 3 \\
\hline EATQ-R & & & \\
$\quad$ Inhibitory control & 0.80 & & \\
Attention & 0.75 & & \\
Activation control & 0.73 & & \\
Frustration & -0.70 & & \\
Pleasure sensitivity & & 0.75 & -0.43 \\
Affiliation & & 0.72 & 0.79 \\
Fearfulness & -0.43 & 0.58 & 0.61 \\
Perceptual sensitivity & & 0.53 & -0.58 \\
High intensity pleasure & & & \\
Activity level & & & \\
Shyness & & & \\
\hline
\end{tabular}

$N=1,055$. For reasons of clarity, only factor loadings $>0.40$ are shown. EATQ-R Early Adolescent Temperament Questionnaire-Revised

That is, negative correlations were found between various types of psychopathological symptoms and EATQ-R scales reflecting effortful control (i.e., activation control, attention, and inhibitory control). Not surprisingly, the most substantial correlations were found with SDQ hyperactivity/ inattention problems ( $r$ s between -0.44 and $-0.58, p \mathrm{~s}<$ $0.001)$, whereas links with other symptoms were more modest ( $r$ between -0.16 and -0.49 ). Temperament scales referring to aspects of emotionality (i.e., fearfulness and frustration) were positively linked to symptom scores. The most convincing correlations emerged between fearfulness and RCADS anxiety and SDQ emotional symptoms ( $r$ s

Table 4 Test-retest and parent-child correlations for EATQ-R temperament scales

\begin{tabular}{lcc}
\hline & $\begin{array}{c}\text { Test-retest } \\
\text { stability }^{\mathrm{a}}\end{array}$ & $\begin{array}{c}\text { Parent-child } \\
\text { agreement }^{\mathrm{b}}\end{array}$ \\
\hline EATQ-R & & \\
$\quad$ Activation control & 0.76 & 0.45 \\
Activity level & 0.72 & 0.59 \\
Affiliation & 0.80 & 0.33 \\
Attention & 0.70 & 0.48 \\
Fearfulness & 0.73 & 0.42 \\
Frustration & 0.85 & 0.33 \\
High intensity pleasure & 0.69 & 0.58 \\
Inhibitory control & 0.78 & 0.42 \\
Perceptual sensitivity & 0.55 & 0.33 \\
Pleasure sensitivity & 0.73 & 0.40 \\
Shyness & 0.73 & 0.40 \\
\hline
\end{tabular}

All correlations were significant at $p<0.001$

EATQ-R Early Adolescent Temperament Questionnaire-Revised

${ }^{\mathrm{a}} N=101$

${ }^{\mathrm{b}} N=390$
Table 5 Correlations (corrected for gender) between EATQ-R scales and other personality/temperament scales

\begin{tabular}{lccc}
\hline & BIS & BAS & Behavioral inhibition \\
\hline EATQ-R & & & \\
Activation control & -0.12 & -0.16 & -0.02 \\
Activity level & -0.03 & 0.13 & -0.16 \\
Affiliation & 0.20 & 0.22 & -0.11 \\
Attention & $-0.26^{*}$ & $-0.25^{*}$ & -0.03 \\
Fearfulness & $0.58^{*}$ & $0.25^{*}$ & 0.02 \\
Frustration & $0.56^{*}$ & $0.52^{*}$ & -0.03 \\
High intensity pleasure & -0.13 & $0.29^{*}$ & $-0.32^{*}$ \\
Inhibitory control & $-0.31^{*}$ & $-0.53^{*}$ & 0.18 \\
Perceptual sensitivity & 0.11 & 0.08 & -0.07 \\
Pleasure sensitivity & $0.24^{*}$ & 0.05 & -0.03 \\
Shyness & $0.39^{*}$ & 0.03 & $0.45^{*}$ \\
\hline
\end{tabular}

$N s$ were 240 (BIS/BAS) and 108 (behavioral inhibition).

EATQ-R Early Adolescent Temperament Questionnaire-Revised, BIS behavioral inhibition system, $B A S$ behavioral approach system ${ }^{*} p<0.001$

being 0.66 and 0.50 , respectively, $p \mathrm{~s}<0.001$ ), and between frustration and CRA aggression $(r=0.51, p<0.001)$. Furthermore, prosocial behavior as indexed by the SDQ was positively associated with aspects of effortful control and affiliation ( $r$ s between 0.22 and $0.39, p s<0.001$ ). Finally, positive correlations were observed between shyness and internalizing symptoms (RCADS anxiety/depression and SDQ emotional symptoms ( $r$ s between 0.25 and 0.34 , $p \mathbf{s}<0.001)$ and between perceptual/pleasure sensitivity and RCADS anxiety ( $r$ s being 0.21 and 0.24 , respectively, $p \mathrm{~s}<0.001$ ), whereas negative correlations emerged between activity level and RCADS depression and SDQ peer relationship problems ( $r$ s being -0.26 and -0.23 , respectively, $p \mathbf{s}<0.001$ ).

\section{Discussion}

The present study investigated the reliability and validity of the self-report version of the EATQ-R in children and adolescents. Altogether, it can be concluded that the psychometric properties of the scale are acceptable but certainly liable to improvement. In particular, the internal consistency of various scales needs to be ameliorated, and this could be achieved in two ways. First, some temperament scales are only composed of a restricted set of items, and so it may be useful to add new items in order to more fully cover the characteristics of the pertinent traits. Another possibility is to remove and/or reformulate reversed items. Although such items are included to tackle response tendencies, there is also evidence suggesting that children and young adolescents have difficulties with reversed items (because of double negation; e.g., Muris et 
Table 6 Correlations (corrected for gender) between EATQ-R temperament scales and psychopathology questionnaires

\begin{tabular}{|c|c|c|c|c|c|c|c|c|}
\hline & $\begin{array}{l}\text { RCADS } \\
\text { anxiety }\end{array}$ & $\begin{array}{l}\text { RCADS } \\
\text { depression }\end{array}$ & $\begin{array}{l}\text { CRA } \\
\text { aggression }\end{array}$ & SDQ conduct & $\begin{array}{l}\text { SDQ } \\
\text { hyperactive }\end{array}$ & SDQ peer & $\begin{array}{l}\text { SDQ } \\
\text { emotional }\end{array}$ & $\begin{array}{l}\text { SDQ } \\
\text { prosocial }\end{array}$ \\
\hline \multicolumn{9}{|l|}{ EATQ-R } \\
\hline Activation control & $-0.34 *$ & $-0.29 *$ & $-0.39^{*}$ & $-0.42 *$ & $-0.52 *$ & $-0.26^{*}$ & $-0.31^{*}$ & $0.34^{*}$ \\
\hline Activity level & -0.05 & $-0.26^{*}$ & -0.06 & -0.11 & -0.01 & $-0.23^{*}$ & -0.16 & 0.18 \\
\hline Affiliation & 0.05 & -0.11 & -0.14 & -0.14 & -0.01 & -0.14 & 0.06 & $0.39 *$ \\
\hline Attention & $-0.42 *$ & $-0.37^{*}$ & $-0.41^{*}$ & $-0.40^{*}$ & $-0.58 *$ & $-0.32 *$ & $-0.40^{*}$ & $0.32 *$ \\
\hline Fearfulness & $0.66^{*}$ & $0.31 *$ & 0.17 & $0.26^{*}$ & $0.21 *$ & $0.34 *$ & $0.50^{*}$ & -0.03 \\
\hline Frustration & $0.43^{*}$ & $0.22 *$ & $0.51 *$ & $0.33^{*}$ & $0.38 *$ & 0.17 & $0.31 *$ & -0.14 \\
\hline High intensity pleasure & -0.16 & -0.12 & 0.08 & 0.06 & 0.06 & -0.13 & -0.18 & 0.03 \\
\hline Inhibitory control & $-0.38^{*}$ & $-0.22 *$ & $-0.49 *$ & $-0.31 *$ & $-0.44 *$ & -0.16 & $-0.29^{*}$ & $0.22 *$ \\
\hline Perceptual sensitivity & $0.21 *$ & 0.08 & 0.12 & 0.04 & 0.06 & -0.00 & 0.07 & 0.04 \\
\hline Pleasure sensitivity & $0.24 *$ & 0.09 & 0.01 & -0.11 & -0.07 & 0.11 & 0.08 & 0.16 \\
\hline Shyness & $0.34^{*}$ & $0.25^{*}$ & 0.17 & 0.06 & 0.15 & 0.17 & $0.34 *$ & -0.13 \\
\hline
\end{tabular}

$N s$ were 390 (RCADS and CRA) and 350 (SDQ).

EATQ-R Early Adolescent Temperament Questionnaire-Revised, RCADS Revised Child Anxiety and Depression Scale, CRA Child Rating of Aggression, $S D Q$ Strengths and Difficulties Questionnaire, Conduct conduct problems, Hyperactive hyperactivity/inattention problems, Peer peer relationship problems, Emotional emotional symptoms, Prosocial prosocial behavior ${ }^{*} p<0.001$

al. 2001a). Indeed, closer inspection of the 'bad' items of the EATQ-R revealed a relatively high percentage of reversed items $(25.8 \%)$ that had to be removed from the questionnaire, whereas the percentage of discarded normal items was only $10.8 \%$. Of course, one could also argue that the psychometrics of the EATQ-R were less optimal because items were translated into the Dutch language (see also Veenstra et al. 2006). This argument can be countered by pointing at the careful translation/backtranslation procedure that was followed and by noting that the obtained psychometrics did not deviate substantially from those reported for the English version of the scale (Ellis and Rothbart 2001).

The results of the principal components analyses justify the conclusion that the structure underlying the self-report version of the EATQ-R was not completely as hypothesized. This may have to do with the above mentioned point that some items of the questionnaire are less optimal and as a consequence certain temperament traits are not expressed very well. Further, the EATQ-R includes a number of scales that seem to be less clear-cut indicators of the main temperament traits of emotionality, extraversion, and effortful control. For example, a trait such as perceptual sensitivity would be indicative of effortful control (Rothbart 2007), but the link between the "detection or perceptual awareness of low-intensity stimulation" (i.e., perceptual sensitivity) and children's regulation of emotions and behavior (which seems to be the central feature of effortful control) is not immediately clear. It may well be that with the inclusion of such ambiguous traits, the questionnaire has become too complex thereby hindering the emergence of a clear-cut factor structure. Note that some support was found for this idea as an additional analysis conducted on the more straightforward emotionality, extraversion, and effortful control scales of the EATQ-R clearly revealed support for the hypothesized three-factor model (see also Kim et al. 2003).

The test-retest stability of the EATQ-R was acceptable. Scores on the EATQ-R remained unchanged over the 8 -weeks period, and most correlations between temperament scores on occasion 1 and 2 were found to be moderate to good. Previous research by Rothbart et al. (2001) has indicated that parent reports of these temperament traits in younger children (as indexed with the Children's Behavior Questionnaire) remain fairly stable over a 2-year period (with test-retest $r$ s between 0.50 and 0.79 ), and this seems to indicate that they reflect enduring characteristics in youths. The parent-child agreement was fairly low and comparable to that reported by Ellis and Rothbart (2001). Two possibilities suggest themselves to account for this finding. First, it may well be the case that children and parents conceive EATQ-R items in different ways. Second, it is also possible that parents have too little insight in the hidden elements of their child's temperament (Achenbach et al. 1987; De Los Reyes and Kazdin 2005). At the very least, this implies that when assessing youths' temperament, it seems important to employ a multi-informant approach.

With regard to the personality and psychopathology correlates of the EATQ-R a number of remarks are in order. To begin with, EATQ-R temperament scales were in a meaningful way related to Gray's (1991) BIS/BAS dimensions and Kagan's (1994) construct of behavioral inhibition. That is, the EATQ-R emotionality scales of fear and frustration were positively associated with BIS, extraversion/ 
surgency scales were particularly associated with BAS, while EATQ-R shyness was significantly linked to behavioral inhibition. Further, relations between the EATQ-R and psychopathological symptoms were also as anticipated. That is, emotionality-related temperament traits were positively connected to internalizing and externalizing symptoms, whereas effortful control-based traits were negatively related to such symptoms (e.g., Eisenberg et al. 1996, 2001; Oldehinkel et al. 2004, 2006; Valiente et al. 2003). Some indications were found for the specificity of the links between temperament traits and psychopathological symptoms: for example, fearfulness was most convincingly linked to anxiety symptoms, whereas frustration was most clearly connected to aggression (see also Muris et al. 2007). In addition, effortful control-based scales and affiliation were found to be positively associated with children's prosocial behavior, which of course supports the idea that high levels of regulation and striving for warm closeness to others are accompanied by high levels of positive social behavior. Finally, a number of correlations were found that were not directly anticipated. That is, BIS and anxiety scores were positively related to pleasure sensitivity, which nevertheless makes sense as youths with high levels of BIS and anxiety symptoms may have a preference for 'safe' activities and stimuli which are characterized by low intensity, complexity, and novelty. Anxiety scores were also positively linked to perceptual sensitivity, which is in keeping with the notion that high-anxious individuals display increased vigilance to environmental stimuli as they might signal impending danger (Vasey and MacLeod 2001). Altogether, these results on the personality and psychopathology correlates of the EATQ-R provide support for the validity of the scale.

Admittedly, the present study suffered from various shortcomings. First, this study only included non-clinical youth. It would be interesting to employ the EATQ-R for measuring reactive and regulative temperament characteristics in clinically referred youths. Second, while the EATQ-R is originally designed for children and adolescents aged 9 to 15 years, most participants in the present study were 10 to 12 years old (i.e., $86.7 \%$ ). It is possible that the psychometrics of the questionnaire would have been better if the sample had included more older youths who generally possess better reading skills. However, during the administration of the EATQ-R, youths asked very few questions, which suggests that they understood the items of this measure rather well. Third, it can be argued that the correlations between temperament and psychopathology scales are largely the result of item overlap. However, recent studies (Lemery et al. 2002; Lengua et al. 1998) have demonstrated that even after eliminating such measurement confounding, temperament traits are still significantly related to children's symptom levels. Fourth, EATQ-R scores were mainly correlated to other self-report scales of personality and psychopathology. Although this is a legitimate approach to investigate the validity of a selfreport scale, the results would have been more compelling if data from parents and teachers had been collected. Finally, several scales were administered to assess various types of symptoms in youths, but only one questionnaire was included to measure the more positive features of youths (i.e., the SDQ prosocial behavior scale). The inclusion of scales measuring self-esteem, emotion regulation, and emotional intelligence would certainly have yielded more information on the validity of EATQ-R scales measuring regulative temperament traits. Despite these limitations, it can be concluded that the self-report version of the EATQ-R seems to be a useful scale for measuring reactive and regulative temperament in children and adolescents aged 9 years and above. Admittedly, there seems to be room for improving the psychometric qualities of the measure, but acknowledging the fact that it is important to assess temperament from youths' own point-of-view, this seems to be a worthwhile scientific endeavor.

Open Access This article is distributed under the terms of the Creative Commons Attribution Noncommercial License which permits any noncommercial use, distribution, and reproduction in any medium, provided the original author(s) and source are credited.

\section{References}

Achenbach, T. M., McConaughy, S. H., \& Howell, C. T. (1987). Child/adolescent behavioral and emotional problems: Implications of cross-informant correlations for situational specificity. Psychological Bulletin, 101, 213-232.

Bates, J. E. (1987). Temperament in infancy. In J. D. Osofsky (Ed.), Handbook of infant development (pp. 1101-1149). New York: Wiley.

Brown, K., Atkins, M. S., Osborne, M. L., \& Milnamow, M. (1996). A revised teacher rating scale for reactive and proactive aggression. Journal of Abnormal Child Psychology, 24, 473-480.

Buss, A. H., \& Plomin, R. (1984). Temperament: Early developing personality traits. Hillsdale: Erlbaum.

Capaldi, D. M., \& Rothbart, M. K. (1992). Development and validation of an early adolescent temperament measure. Journal of Early Adolescence, 12, 153-173.

Carver, C. S., \& White, T. L. (1994). Behavioral inhibition, behavioral activation, and affective responses to impending reward and punishment. Journal of Personality and Social Psychology, 67, 319-333.

Carver, C. S., \& Scheier, M. F. (1996). Perspectives on personality. Boston: Allyn and Bacon.

Caspi, A. (2000). The child is father of the man: Personality continues from childhood to adulthood. Journal of Personality and Social Psychology, 78, 158-172.

Caspi, A., \& Silva, P. A. (1995). Temperamental qualities at age 3 predict personality traits in young adulthood: Longitudinal evidence from a birth cohort. Child Development, 66, 486-498. 
Caspi, A., Harrington, H., Milne, B., Amell, J. W., Theodore, R. F., \& Moffitt, T. E. (2003). Children's behavioral styles at age 3 are linked to their adult personality traits at age 26. Journal of Personality, 71, 495-513.

Chess, S., \& Thomas, A. (1985). Temperament in clinical practice. New York: Guilford.

Chorpita, B. F., Yim, L., Moffitt, C., Umemoto, L. A., \& Francis, S. E. (2000). Assessment of symptoms of DSM-IV anxiety and depression in children: A revised child anxiety and depression scale. Behaviour Research and Therapy, 38, 835-855.

Costa, P. T., \& McCrae, R. R. (1992). Revised NEO personality inventory and NEO five-factor inventory professional manual. Odessa, FL: Psychological Assessment Resources.

De Los Reyes, A., \& Kazdin, A. E. (2005). Informant discrepancies in the assessment of childhood psychopathology: A critical review, theoretical framework, and recommendations for further study. Psychological Bulletin, 131, 483-509.

Eisenberg, N., Fabes, R. A., Guthrie, I. K., Murphy, B. C., Maszk, P., Holmgren, R., et al. (1996). The relations of regulation and emotionality to problem behavior in elementary school children. Development and Psychopathology, 8, 141-162.

Eisenberg, N., Cumberland, A., Spinrad, T. L., Fabes, R. A., Shepard, S. A., Reiser, M., et al. (2001). The relations of regulation and emotionality to children's externalizing and internalizing behaviour problems. Child Development, 72, 1112-1134.

Eisenberg, N., Liew, J., \& Pidada, S. U. (2004a). The longitudinal relations of regulation and emotionality to quality of Indonesian children's socioemotional functioning. Developmental Psychology, 40, 790-804.

Eisenberg, N., Smith, C. L., Sadovsky, A., \& Spinrad, T. L. (2004b). Effortful control. Relations with emotion regulation, adjustment, and socialization in childhood. In R. Baumeister, \& K. Vohs (Eds.), Handbook of self-regulation. Research, theory, and applications (pp. 259-282). New York: Guilford.

Ellis, L. K., \& Rothbart, M. K. (2001). Revision of the Early Adolescent Temperament Questionnaire. Poster presented at the Biennial Meeting of the Society for Research in Child Development. Minneapolis, Minnesota.

Else-Quest, N. M., Hide, J. S., Goldsmith, H. H., \& Van Hulle, C. A. (2006). Gender differences in temperament: A meta-analysis. Psychological Bulletin, 132, 33-72.

Eysenck, H. J. (1991). Dimensions of personality: 16, 5 or 3? Criteria for a taxonomic paradigm. Personality and Individual Differences, $12,773-790$.

Fabes, R. A., Eisenberg, N., Jones, S., Smith, M., Guthrie, I., Poulin, R., et al. (1999). Regulation, emotionality, and preschoolers' socially competent peer interactions. Child Development, 70, 432-442.

Garnstein, M. A., \& Rothbart, M. K. (2003). Studying infant temperament via the Revised Infant Behavior Questionnaire. Journal of Infant Behavior and Development, 26, 64-86.

Gest, S. D. (1997). Behavioral inhibition: Stability and associations with adaptation from childhood to early adulthood. Journal of Personality and Social Psychology, 72, 467-475.

Goodman, R. (2001). Psychometric properties of the Strengths and Difficulties Questionnaire. Journal of the American Academy of Child and Adolescent Psychiatry, 40, 1337-1345.

Gray, J. A. (1991). The neuropsychology of temperament. In J. Strelau, \& A. Angleiter (Eds.), Explorations in temperament: International perspectives in theory and measurement (pp. 105128). New York: Plenum.

Guthrie, I. K., Eisenberg, N., Fabes, R. A., Murphy, B. C., Holmgren, R., Maszk, P., et al. (1997). The relations of regulation and emotionality to children's situational empathy-related responding. Motivation and Emotion, 21, 87-108.
Kagan, J. (1994). Galen's prophecy: Temperament in human nature. New York: Basic Books.

Kim, S., Brody, G. H., \& McBride Murry, V. (2003). Factor structure of the Early Adolescent Temperament Questionnaire and measurement invariance across gender. Journal of Early Adolescence, 23, 268294.

Kochanska, G. (1997). Multiple pathways to conscience for children with different temperaments: From toddlerhood to age 5 . Developmental Psychology, 33, 228-240.

Korchnakova, K. (2007). Further evidence for the psychometric properties of the Child Rating scale for Aggression. Unpublished master thesis, Erasmus University Rotterdam.

Lemery, K. S., Essex, M. J., \& Smider, N. A. (2002). Revealing the relation between temperament and behavior problem symptoms by eliminating measurement confounding: Expert ratings and factor analyses. Child Development, 73, 867-882.

Lengua, L. J., West, S. G., \& Sandler, I. N. (1998). Temperament as a predictor of symptomatology in children: Addressing contamination of measures. Child Development, 69, 164-181.

Matthews, G., Deary, I. J., \& Whiteman, M. C. (2003). Personality traits (second edition). New York: Cambridge University Press.

Meesters, C., Muris, P., \& Van Rooijen, B. (2007). Relations of neuroticism and attentional control with symptoms of anxiety and aggression in non-clinical children. Journal of Psychopathology and Behavioral Assessment, 29, 149-158.

Muris, P., \& Ollendick, T. H. (2005). The role of temperament in the etiology of child psychopathology. Clinical Child and Family Psychology Review, 8, 271-289.

Muris, P., Merckelbach, H., Wessel, I., \& Van de Ven, M. (1999). Psychopathological correlates of self-reported behavioural inhibition in normal children. Behaviour Research and Therapy, 37, $575-584$.

Muris, P., Meesters, C., \& Gobel, M. (2001a). Reliability, validity, and normative data of the Penn State Worry Questionnaire in 8- to 12-year old children. Journal of Behavior Therapy and Experimental Psychiatry, 32, 63-72.

Muris, P., Merckelbach, H., Schmidt, H., Gadet, B., \& Bogie, N. (2001b). Anxiety and depression as correlates of self-reported behavioural inhibition in normal adolescents. Behaviour Research and Therapy, 39, 1051-1061.

Muris, P., Meesters, C., \& Schouten, E. (2002). A brief questionnaire of DSM-IV defined anxiety and depression symptoms among children. Clinical Psychology and Psychotherapy, 9, 430-442.

Muris, P., Meesters, C., \& Spinder, M. (2003a). Relationships between child- and parent-reported behavioural inhibition and symptoms of anxiety and depression in normal adolescents. Personality and Individual Differences, 34, 759-771.

Muris, P., Meesters, C., \& Van den Berg, F. (2003b). The Strengths and Difficulties Questionnaire (SDQ): Further evidence for its reliability and validity in a community sample of Dutch children and adolescents. European Child and Adolescent Psychiatry, 12, $1-8$.

Muris, P., Meesters, C., Eijkelenboom, A., \& Vincken, M. (2004). The self-report version of the Strengths and Difficulties Questionnaire: Its psychometric properties in 8- to 13-year-old children. British Journal of Clinical Psychology, 43, 437-438.

Muris, P., Meesters, C., De Kanter, E., \& Eek Timmerman, P. (2005). Behavioural inhibition and behavioural activation system scales for children: Relationships with Eysenck's personality traits and psychopathological symptoms. Personality and Individual Differences, 38, 831-841.

Muris, P., Meesters, C., \& Blijlevens, P. (2007). Self-reported reactive and regulative temperament in early adolescence: Relations to internalizing and externalizing problem behavior and "Big Three" personality factors. Journal of Adolescence, 30, 1035-1049. 
Nigg, J. T. (2006). Temperament and developmental psychopathology. Journal of Child Psychology and Psychiatry, 47, 395-422.

Oldehinkel, A. J., Hartman, C., De Winter, A. F., Veenstra, R., \& Ormel, J. (2004). Temperament profiles associated with internalizing and externalizing problems in preadolescence. Development and Psychopathology, 16, 421-440.

Oldehinkel, A. J., Veenstra, R., Ormel, J., De Winter, A. F., \& Verhulst, F. C. (2006). Temperament, parenting, and depressive symptoms in a population sample of preadolescents. Journal of Child Psychology and Psychiatry, 47, 684-695.

Putnam, S. P., \& Rothbart, M. K. (2006). Development of short and very short forms of the Children's Behavior Questionnaire. Journal of Personality Assessment, 87, 103-113.

Putnam, S. P., Ellis, L. K., \& Rothbart, M. K. (2002). The structure of temperament from infancy through adolescence. In A. Eliasz, \& A. Angleitner (Eds.), Advances in research on temperament (pp. 165-182). Germany: Pabst Science.

Putnam, S. P., Garnstein, M. A., \& Rothbart, M. K. (2006). Measurement of fine-grained aspects of toddler temperament: The Early Childhood Behavior Questionnaire. Infant Behavior and Development, 29, 386-401.

Roelofs, J., Meesters, C., Ter Huurne, M., Bamelis, L., \& Muris, P. (2006). On the links between attachment style, parental rearing behaviors, and internalizing and externalizing problems in nonclinical children. Journal of Child and Family Studies, 15, 319-332.

Rothbart, M. K. (1981). Measurement of temperament in infancy. Child Development, 52, 569-578.

Rothbart, M. K. (1989). Temperament and development. In G. A. Kohnstamm, J. E. Bates, \& M. K. Rothbart (Eds.), Temperament in childhood (pp. 187-247). New York: Wiley.

Rothbart, M. K. (2007). Temperament, development, and personality. Current Directions in Psychological Science, 16, 207-212.

Rothbart, M. K., \& Derryberry, D. (1981). Development of individual differences in temperament. In M. E. Lamb, \& A. L. Brown (Eds.), Advances in developmental psychology (vol. 1, (pp. 3786)). Hillsdale: Erlbaum.

Rothbart, M. K., \& Bates, J. E. (1998). Temperament. In N. Eisenberg, \& W. Damon (Eds.), Handbook of child psychology: Volume 3. Social, emotional, and personality development (pp. 105-176). New York: Wiley.

Rothbart, M. K., \& Bates, J. E. (2006). Temperament. In N. Eisenberg, W. Damon, \& R. M. Lerner (Eds.), Handbook of child psychology: Volume 3. Social, emotional, and personality development (pp. 99-166). Hoboken, NJ: Wiley.
Rothbart, M. K., Derryberry, D., \& Posner, M. I. (1994). A psychobiological approach to the development of temperament In J. E. Bates, \& T. D. Wachs (Eds.), Temperament: Individual differences at the interface of biology and behavior (pp. 83-116). Washington, DC: American Psychological Association.

Rothbart, M. K., Ahadi, S. A., \& Evans, D. E. (2000). Temperament and personality: Origins and outcomes. Journal of Personality and Social Psychology, 78, 122-135.

Rothbart, M. K., Ahadi, S. A., Hershey, K. L., \& Fisher, P. (2001). Investigations of temperament at three to seven years: The Children's Behavior Questionnaire. Child Development, 72, 1394-1408.

Rothbart, M. K., Posner, M. I., \& Kieras, J. (2006). Temperament, attention, and the development of self-regulation. In K. McCartney, \& D. Phillips (Eds.), Blackwell handbook of early childhood development (pp. 338-357). Malden, MA: Blackwell.

Thomas, A., \& Chess, S. (1977). Temperament and development. New York: Brunner/Mazel.

Valiente, C., Eisenberg, N., Smith, C. L., Reiser, M., Fabes, R. A., Losoya, S., et al. (2003). The relations of effortful control and reactive control to children's externalizing problems: A longitudinal assessment. Journal of Personality, 71, 1171-1196.

Van Brakel, A., \& Muris, P. (2006). A brief scale for measuring "behavioral inhibition to the unfamiliar" in children. Journal of Psychopathology and Behavioral Assessment, 28, 79-84.

Van Brakel, A., Muris, P., \& Bögels, S. (2004). Relations between parent- and teacher-reported behavioral inhibition and behavioral observations of this temperamental trait. Journal of Clinical Child and Adolescent Psychology, 33, 579-589.

Vasey, M. W., \& MacLeod, C. (2001). Information-processing factors in childhood anxiety: A review and developmental perspective. In M.W. Vasey, \& M. Dadds (Eds.), The developmental psychopathology of anxiety (pp. 253-277). New York: Oxford University Press.

Veenstra, R., Lindenberg, S., Oldehinkel, A. J., De Winter, A. F., \& Ormel, J. (2006). Temperament, environment, and antisocial behavior in a population sample of preadolescent boys and girls. International Journal of Behavioral Development, 30, 422-432.

Vincken, M., Eijkelenboom, A., Muris, P., \& Meesters, C. (2004). 'Zelfcontrole': Een effectief interventie-programma voor kinderen met agressief en oppositioneel gedrag (Self-control. An effective intervention program for children with aggressive and oppositional behavior problems). Kind en Adolescent Praktijk, 3, $17-23$. 